Document downloaded from:

http://hdl.handle.net/10251/104484

This paper must be cited as:

Bayón Barrachina, A.; Toro, J.; Bombardelli, F.; Matos, J.; López Jiménez, PA. (2017).

Influence of VOF technique, turbulence model and discretization scheme on the numerical simulation of the non-aerated, skimming flow in stepped spillways. Journal of HydroEnvironment Research (Online). 19:137-149. doi:10.1016/j.jher.2017.10.002

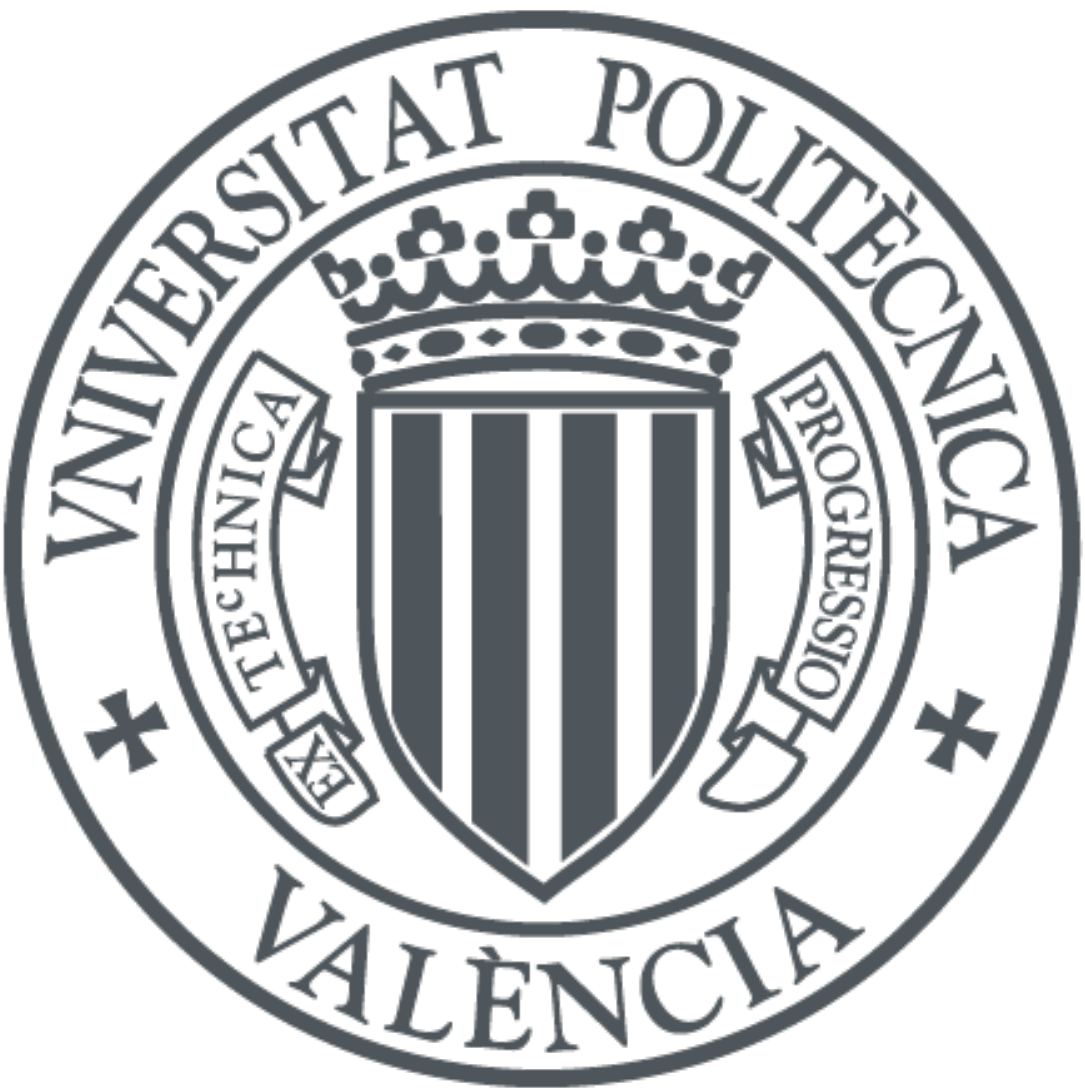

The final publication is available at

http://doi.org/10.1016/j.jher.2017.10.002

Copyright Elsevier

Additional Information 


\section{Influence of VOF technique, turbulence model and discretization scheme on the numerical simulation of the non-aerated, skimming flow in stepped spillways}

Arnau Bayon, ${ }^{1, *}$ Juan Pablo Toro, ${ }^{2}$ Fabián A. Bombardelli, ${ }^{3}$ Jorge Matos, ${ }^{4}$ and Petra Amparo López-Jiménez $^{5}$

${ }^{1}$ Research Institute of Water and Environmental Engineering (IIAMA). Universitat Politècnica de València, Camí de Vera, s/n, 46022, València, Spain (arbabar@iiama.upv.es)

${ }^{2}$ Assistant Professor, Department of Civil Engineering, Universidad Andres Bello, Santiago 8320000, Chile; formerly, Ph.D. Candidate, Department of Civil and Environmental Engineering, Univ. of California, 2001 Ghausi Hall, One Shields Ave., Davis, CA 95616. E-mail: juan.toro.1@unab.cl

${ }^{3}$ Department of Civil and Environmental Engineering, University of California, Davis, USA (fabianbombardelli2@gmail.com)

${ }^{4}$ Department of Civil Engineering, Architecture and Georesources, Instituto Superior Técnico, Universidade de Lisboa, Av. Rovisco Pais 1, 1049-001, Lisboa, Portugal (jorge.matos@tecnico.ulisboa.pt)

${ }^{5}$ Department of Hydraulic and Environmental Engineering, Universitat Politècnica de València, Camí de Vera, s/n, 46022, València, Spain (palopez@upv.es)

*Corresponding author

\section{Abstract}

An accurate description of the hydrodynamics in the non-aerated region of the skimming flow on stepped spillways is of outmost importance, particularly in small structures at large discharges. In addition, the flow features upstream of the inception point of air entrainment determine the flow behavior in the downstream self-aerated region. In this work, numerical models of the flow in the non-aerated region of stepped spillways have been developed using diverse turbulence closures and discretization schemes implemented in two CFD codes: OpenFOAM and FLOW-3D ${ }^{\circledR}$. Partial VOF (Volume of Fluid) and "True" VOF (TruVOF) approaches are employed to capture the position of the free surface. The Standard, RNG and Realizable $k-\varepsilon$, in addition to the SST k- $\omega$ 
9

model, are used for turbulence closure. Numerical results are compared against reference experimental results obtained from a physical model of constant slope of $0.75 \mathrm{H}: 1 \mathrm{~V}$. Models with turbulence closures of the $k-\varepsilon$ family provide nearly the same predictions for the mean flow velocity with maximum differences on average smaller than $1 \%$. Regarding discretization schemes, the first-order upwind method provides predictions for the mean flow velocity which are not significantly different (within 6\%) than those obtained with second-order counterparts. However, these differences can be larger when maximum values of turbulent kinetic energy (TKE) and dissipation rate of TKE at the step edges are compared. In spite of the fact that the TruVOF $\left(F L O W-3 D^{\circledR}\right)$ method does not account for the tangential stresses at the air-water interface, differences in the tracking of the free surface position among this method and the Partial VOF method (OpenFOAM) were found to be smaller than 3\% along the stepped spillway. In this work, we also provide a physical interpretation of the flow results.

Keywords: Stepped spillway; Computational Fluid Dynamics (CFD); OpenFOAM; FLOW-3D; RANS; VOF.

\section{Introduction}

Stepped spillways have been used for centuries as multi-purpose hydraulic structures: flow energy dissipation, aesthetics, flood evacuation, etc. (Chanson, 2002). It was not until last century, in concomitance with the spreading of new construction methodologies, such as roller compacted concrete (RCC), that stepped spillways became an appealing way to dissipate energy (Chanson et al., 2015; Matos \& Meireles, 2014). 
The presence of macro-roughness elements increases the rate of boundary-layer development

in the stepped spillway, thus displacing upstream the inception point of air entrainment; i.e., the section where the boundary layer encounters the water free surface and eddies possess enough energy to distort it (Meireles et al., 2014).

So far, most of the studies in the literature have been based on experimental modeling in the self-aerated, skimming flow region (see e.g., Chanson, 2002; Matos \& Meireles, 2014; Chanson et al., 2015). Such studies have been able to provide clear insight into relevant subjects, such as location of the inception of air entrainment, air concentration and velocity distributions, pressure distribution on the step faces, flow resistance and energy dissipation.

The quantity of studies dealing with the non-aerated part of the flow is limited (Amador, 2005; Amador et al., 2006; Bombardelli et al., 2011; Carvalho \& Amador, 2009; Hunt \& Kadavy, 2010; Meireles \& Matos, 2009; Toro et al., 2016; Zhang \& Chanson, 2016a, 2016b). This fact is to a certain extent justified, as on most prototype applications self-aeration would occur in a considerable portion of the chute for the design discharge. Nevertheless, in some real-life cases, especially in small structures at large discharges, the non-aerated flow can dominate most of the length of the flow (Bombardelli et al., 2011; Meireles et al., 2014). Characterizing the non-aerated region of the flow is also important with regard to cavitation. Recent studies showed that if flow velocities in the non-aerated skimming flow region are large enough, cavitation and related damage on the step surfaces may occur (Frizell et al. 2013, 2015). In addition, an accurate description of maximum velocities and turbulence statistics close to the inception point of air entrainment is crucial for the understanding of the flow features downstream of the inception point (Toro et al., 2016). To the best of the Authors' knowledge, a full and comprehensive description of the flow features in the aerated zone has not been achieved so far. 
Recent numerical works focusing on the non-aerated region have provided good predictions of time-averaged velocities, water depths, development of the boundary layer and turbulence statistics (Bombardelli et al., 2011; Meireles, 2011; Toro et al., 2016). However, relatively little emphasis has been put into the influence of the VOF technique, the turbulence closure and the discretization schemes on the numerical results. There is the natural question as to whether these variables exert significant differences in the prediction of the main flow properties in such region. In this paper, a new two-dimensional (2D) CFD model of the skimming flow in the non-aerated region on stepped spillways is presented. Incompressible turbulent flow is assumed and the free surface is captured by means of Partial- and Complete-VOF methods (Bombardelli et al., 2001; Hirt \& Nichols, 1981). The theoretical model is implemented in the open source toolbox OpenFOAM and the numerical results are compared against a dataset collected at a facility assembled at the National Laboratory of Civil Engineering (LNEC), in Lisbon, Portugal, available in Matos (1999), Meireles (2004, 2011), and Renna (2004). Further, those numerical data are compared with counterparts obtained with the use of the code $F L O W-3 D^{\circledR}$ (Bombardelli et al., 2011). A model sensitivity analysis to different turbulence closures and discretization schemes is performed and discussed. To the best of the Authors' knowledge, such a thorough comparison among different VOF approaches, turbulence models and discretization schemes to determine which of them performs best has not been conducted so far. The flow self-similarity at various locations of the spillway is also assessed by analyzing the flow turbulence properties.

It is believed that results of this research provides answers regarding very-important, current discussions on how to model the non-aerated portion of stepped spillways, given the theoretical models included in some codes and packages. 
The experimental facility used for validation of the numerical model presented herein was built at LNEC, in Lisbon, Portugal. The experimental results have been already published elsewhere (e.g., Meireles, 2004, 2011; Bombardelli et al., 2011; Meireles et al., 2012, 2014), so only a brief summary is provided in this section.

The facilities consisted of a reservoir, and a smooth crest following the profile of the Waterways Experimental Station (WES). The first steps downstream of the crest had variable size for their edges to fit the WES profile, as depicted in Fig. 1. A tangent point was defined downstream, where the WES profile presented uniform steps. These steps were $3 \mathrm{~cm}$ long and 4 $\mathrm{cm}$ tall, defining a chute slope of $1 \mathrm{~V}: 0.75 \mathrm{H}$. The total height of the device, from crest to toe, was $2.9 \mathrm{~m}$ and had a constant width of $1 \mathrm{~m}$.

Measurements were taken using a conductivity probe and a back-flushing Pitot tube held in such a way that measurements could be taken parallel to the spillway pseudo-bottom (see Fig. 2). Even though this work focuses on the non-aerated region of the flow, air concentration measurements helped both to determine the equivalent clear-water depth and to correct differential pressure data in the wavy region. A more thorough discussion on the experimental setup is available in Matos (1999), Meireles (2004, 2011), Renna (2004), Bombardelli et al.

119 (2011), and Meireles et al. (2012, 2014). For the current paper, data presented in Bombardelli et 120 al. (2011), and collected in the framework of Meireles (2004), was considered for the 121 comparative analysis. 


\section{Theoretical and numerical models}

\subsection{Flow model}

In cases where large domains have to be modeled and no special attention is paid to what occurs at very small time and spatial scales, which generally takes place in most engineering applications, the turbulence averaging of the flow variables in the Navier-Stokes Equations, the socalled Reynolds-Averaged Navier-Stokes (RANS), constitutes the best choice. The RANS

131 Equations [Eqs. (1) and (2) below] are thus solved in this paper. The mass and momentum

132 equations are expressed in vector/tensor notation in the following form, respectively:

$133 \nabla \cdot \underline{\bar{u}}=0$

$134 \quad \frac{\partial \underline{\overline{\mathrm{u}}}}{\partial \mathrm{t}}+\underline{\overline{\mathrm{u}}} \cdot \nabla \underline{\mathrm{u}}=-\frac{1}{\rho} \nabla \overline{\mathrm{p}}+\frac{1}{\rho} \nabla \cdot\left(\underline{\underline{\bar{\tau}}}+\underline{\underline{\tau}}^{\mathrm{R}}\right)+\overline{\mathrm{f}_{\mathrm{b}}}$

135 where $\underline{\overline{\mathrm{u}}}$ is the time-averaged velocity vector, $\overline{\mathrm{p}}$ is pressure, $\rho$ indicates the density, $\mathrm{t}$ is time, $\underline{\underline{\tau}}$

136 refers to the averaged, deviatoric stress tensor, $\underline{\underline{\tau}}^{\mathrm{R}}$ is the Reynolds stress tensor and $\overline{\mathrm{f}_{\mathrm{b}}}$ is the 137 gravity force. Surface tension was not included because Weber numbers were always above 110 138 (see Boes \& Hager, 2003), thus indicating that this force does not exert a large effect on the flow.

3.2 Free surface modeling

One of the most widely-used methods to capture the position of the free surface is the so-called

143 VOF (Volume of Fluid) method, developed by Hirt and Nichols (1981). This technique is based on 144 three elements: a) the definition of the volume of fluid function $(\alpha)$, which is equal to one when the computational volume is occupied by water, zero when it is air and in between zero and one when the volume is occupied by both air and water; b) the imposition of boundary conditions (i.e., 
pressure) at the unknown free surface; and c) the use of an accurate numerical scheme to avoid numerical diffusion of the free surface solution (Bombardelli et al., 2001). Small variants of this method (improvements) are implemented in $F L O W-3 D^{\circledR}$, named as TruVOF by the developers (FLOW-3D ${ }^{\circledR}$ User Manual, 2016), and those variants have demonstrated their validity in a wide range of hydraulic engineering applications (Bombardelli et al., 2001, 2011; Rodríguez et al., 2004). The VOF method implemented in $F L O W-3 D^{\circledR}$ has all three ingredients mentioned above. In particular, the implementation of free-surface boundary conditions requires special care to avoid numerical instabilities; further, from the physical point of view, it better reflects the fact that, with the exception of a (thin) boundary layer, water and air generally move independently of each other. both the water and air flows are solved (Bombardelli et al., 2001). This approach presents certain advantages such as accounting for air-water shear stresses; however, it increases the model overall computational cost and may introduce erroneous descriptions in some cases, namely, the simulation of jets coming out of nozzles (Bombardelli et al., 2001).

161 In the TruVOF, the transport of $\alpha$ in the simulated domain is represented by using the 162 following advection equation:

$163 \frac{\partial \alpha}{\partial \mathrm{t}}+\nabla \cdot(\underline{\overline{\mathrm{u}}} \alpha)=0$

164 where $\underline{\underline{u}}$ is the velocity of water. In the Partial VOF method implemented in OpenFOAM, the 165 velocity $\underline{\underline{u}}$ is the shared velocity of the two-phase flow. In this Partial VOF method, all variables in 166 each volume, e.g., $\xi$, are weighted according to the fluid fraction for each fluid A and B:

168 In the case of OpenFOAM, an extra velocity term is added perpendicularly to the water free surface

169 to help to compress it: $\nabla \cdot\left(\underline{\overline{u_{\mathrm{c}}}} \alpha[1-\alpha]\right)$. The term $\alpha[1-\alpha]$ ensures that the compression velocity 
170 only affects those regions where flow fractions are close to 0.5 (Rusche, 2002). The compression

171 velocity term is computed according to a method based on the theory of two-phase flow

172 (Berberovic et al., 2009):

$173 \quad \underline{\mathrm{u}_{\mathrm{c}}}=|\underline{\mathrm{u}}| \frac{\nabla \alpha}{|\nabla \alpha|}$

174 where $|\underline{u}|$ is the mixed flow velocity modulus, although in Berberovic et al. (2009), the term $\underline{u_{c}}$

175 represents the relative velocity between both phases, $\underline{u_{w}}-\underline{u_{a}}$.

176 The free surface position is usually defined at the point where $\alpha=0.5$. More information on free

177 surface modeling can be found in Ubbink (1997), Bombardelli et al. (2001), Rusche (2002) and

178 Berberovic (2010).

179

180

\subsection{Turbulence modeling}

181

Four different turbulence closures are employed in this work, keeping all the other parameters constant, and their results are analyzed and compared. The four assessed models are the Standard

184 k- $\varepsilon$ (Launder \& Sharma, 1974), the Realizable k- $\varepsilon$ (Shih et al., 1995), the RNG k- $\varepsilon$ (Yakhot et al., 1992), and the SST k- $\omega$ (Menter, 1993). The models of the k- $\varepsilon$ family have proven to yield good results in the modeling of hydraulic structures (Bayon et al., 2016; Bayon \& López-Jiménez, 2015; Bombardelli, 2004; Bombardelli et al., 2011; Bradshaw, 1996; Romagnoli et al., 2009; Witt et al., 2015), whereas the SST k- $\omega$ model has been successfully applied by the Authors in a study of a hydraulic jump (Bayon \& López-Jiménez, 2015).

190 The comparative analysis is conducted exclusively using the RNG k- $\varepsilon$ simulations, so that the

191 numerical data obtained with OpenFOAM are equivalent to the results obtained by Bombardelli et 192 al. (2011) using $F L O W-3 D^{\circledR}$. The RNG k- $\varepsilon$ model is a two-equation turbulence model based on the 
193 concept of eddy viscosity $\left(v_{t}=\frac{\mu_{\mathrm{t}}}{\rho}\right)$, where the two additional variables to compute it are $\mathrm{k}$ 194 (turbulent kinetic energy, TKE) and $\varepsilon$ (dissipation rate of TKE). The transport of these two 195 variables is modeled according to the following advection-diffusion-reaction (ADR) equations:

$196 \frac{\partial}{\partial \mathrm{t}}(\rho \mathrm{k})+\nabla \cdot(\rho \mathrm{k} \underline{\bar{u}})=\nabla \cdot\left[\left(\mu+\frac{\mu_{\mathrm{t}}}{\sigma_{\mathrm{k}}}\right) \nabla \mathrm{k}\right]+\mathrm{P}_{\mathrm{k}}-\rho \varepsilon$

$197 \frac{\partial}{\partial \mathrm{t}}(\rho \varepsilon)+\nabla \cdot(\rho \varepsilon \underline{\bar{u}})=\nabla \cdot\left[\left(\mu+\frac{\mu_{\mathrm{t}}}{\sigma_{\varepsilon}}\right) \nabla \varepsilon\right]+\left(\mathrm{C}_{1 \varepsilon}-\mathrm{R}\right) \frac{\varepsilon}{\mathrm{k}} \mathrm{P}_{\mathrm{k}}-\mathrm{C}_{2 \varepsilon} \rho \frac{\varepsilon^{2}}{\mathrm{k}}$

$R=\eta\left(-\eta / \eta_{0}+1\right) /\left(\beta \eta^{3}+1\right) ; \eta=S k / \varepsilon ; S=\left(2 \bar{S}_{i j} \bar{S}_{i j}\right)^{1 / 2}$

199 where $\mathrm{P}_{\mathrm{k}}$ is the production of TKE and $\overline{\mathrm{S}}_{\mathrm{ij}}$ is the strain-rate tensor. The formulation constants are $\sigma_{\mathrm{k}}=0.7194, \sigma_{\varepsilon}=0.7194, \mathrm{c}_{1 \varepsilon}=1.42, \mathrm{c}_{2 \varepsilon}=1.68, \mathrm{C}_{\mu}=0.0845, \eta_{0}=4.38$, and $\beta=0.012$.

201 The eddy viscosity is computed as $v_{t}=C_{\mu} \frac{\mathrm{k}^{2}}{\varepsilon}$.

\subsection{Boundary conditions}

The boundary conditions imposed to the model are as follows. At the inlet, a constant-depth subcritical flow is followed by a stretch of reservoir of $1.2 \mathrm{~m}$ in length (measured from the boundary to the crest of the spillway). This buffer zone is long enough according to the Authors' experience (Bombardelli et al., 2011; Toro et al., 2016). Downstream of the spillway, an outlet boundary condition is imposed, where the flow leaves the domain in supercritical state. With regards to the turbulence model variables, $\mathrm{k}, \varepsilon$ and $\omega$, no measurements are available at the

211 reservoir entrance. Therefore, a Dirichlet boundary condition is set to a low value for the actual 212 profiles to develop along the reservoir buffer stretch.

213 The upper boundary condition of the model is atmospheric and so the flow can freely enter or 214 exit the domain through it; all variables are set to a null von Neumann boundary condition, except 
for pressure, which is set to atmospheric. A smooth no-slip boundary condition is applied to the solid contours of the model (the roughness of the methacrylate of the experimental device is

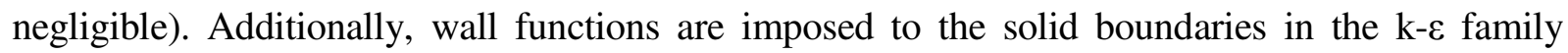
models. The values of $\mathrm{y}^{+}$throughout the entire chute were such that the first node was located outside of the viscous sub-layer, thus ensuring that the wall function was operating as intended. Therefore, all mesh elements in contact with solid boundaries have a $\mathrm{y}^{+}$coordinate at the logarithmic layer, i.e. $\mathrm{y}^{+} \in[30,100]$ (Ferziger \& Peric, 2012; Schlichting \& Gersten, 2000). The $\mathrm{y}^{+}$variable is defined as $\mathrm{y}^{+}=\mathrm{y} \frac{\mathrm{u}_{\tau}}{\mathrm{v}}$, where $\mathrm{y}$ is the distance of the center of the first volume to the wall, $\mathrm{u}_{\tau}$ is the shear velocity, and $v$ is the kinematic viscosity. On the other hand, since the SST k$\omega$ is a low-Reynolds model, a mesh refinement is required for all mesh volumes in contact with solid boundaries, so that the first volume is in the viscous sub-layer.

\subsection{Numerical schemes}

The numerical solution of the equations presented above was developed via the finite-volume method (FVM), and implemented in the code OpenFOAM (OpenFOAM User Guide, 2011). In OpenFOAM, the numerical integration is conducted using the PIMPLE algorithm, a combination of two widely used algorithms: PISO (Issa, 1985) and SIMPLE (Patankar \& Spalding, 1972).

In the present work, three different discretization schemes are used to approximate the advection terms: a) a first-order upwind method; b) the second-order limited Van Leer (1977) method; and c) a second-order limited central difference method. A sensitivity analysis to the numerical discretization scheme is conducted along with the rest of model parameters. 
Time derivatives are discretized using a second-order backward discretization scheme. The diffusive terms of the equations are discretized using a second-order accurate Gauss linear corrected scheme in all cases.

\section{Model implementation}

\subsection{Geometry and mesh}

done in Bombardelli et al. (2011). The mesh employed in the SST k- $\omega$ simulations required additional refinement in the near-wall region to ensure that $\mathrm{y}^{+}$remains within the viscous sublayer. To this end, 10 extra layers of total thickness equal to $1 / 3$ of the normal element size and a growth ratio of 1.175 were added to the elements adjacent to the spillway steps.

In order to fit the mesh to the modeled geometry, the OpenFOAM model uses the tool snappyHexMesh; its use in similar applications has yielded good results (Sweeney, 2014; Toro et al., 2016). The $F L O W-3 D^{\circledR}$ code uses the porosity-based FAVOR method to define solid objects, which, if correctly used, yields accurate results (Bombardelli et al., 2011; Carvalho et al., 2008).

To obtain mesh-independent results, 5 different mesh sizes were used and the grid convergence index (GCI) methodology proposed by Roache (2009) was employed. This procedure, based on the Richardson Extrapolation, is discussed and exemplified in Celik et al. (2008). The grid refinement degree between consecutive sizes is $r=\sqrt{2}$, thus being the global refinement degree $r_{g}=4.0$, above the 1.3 minimum value proposed by Celik et al. (2008). Mesh refinement is conducted 
are summarized in Table 1. Water depths $(d)$ at 6 different locations are used as indicator variables

\begin{tabular}{|c|c|c|c|c|}
\hline Mesh & Horiz. size $(\boldsymbol{\Delta} \mathbf{x})$ & $\begin{array}{c}\text { Vert. size }(\boldsymbol{\Delta y}) \\
(\mathbf{m m})\end{array}$ & $\begin{array}{c}\text { Aspect ratio } \\
(\mathbf{V} / \mathbf{H})\end{array}$ & $\begin{array}{c}\mathbf{h}=\sqrt{\boldsymbol{\Delta} \mathbf{\Delta} \mathbf{y}} \\
(\mathbf{m m})\end{array}$ \\
\hline 1 & 1.06 & 1.41 & $4 / 3$ & 1.22 \\
2 & 1.50 & 2.00 & $4 / 3$ & 1.73 \\
3 & 2.12 & 2.83 & $4 / 3$ & 2.45 \\
4 & 3.00 & 4.00 & $4 / 3$ & 3.46 \\
5 & 4.24 & 5.66 & $4 / 3$ & 4.90 \\
\hline
\end{tabular}

Table 1. Characteristics of the meshes tested in the convergence analysis.

Simulations were compared against the LNEC experimental data for a discharge of $0.18 \mathrm{~m}^{3} / \mathrm{s}$ (specific discharge of $0.18 \mathrm{~m}^{2} / \mathrm{s}$ ). These simulations were run varying only one parameter from one simulation to another in order to capture the effect of that specific parameter.

\section{Analysis of results}

\subsection{Mesh convergence}


comparison of water free surface profiles for $\alpha=0.5$ obtained with different mesh sizes is shown.

277 The apparent order reaches a value of $p_{k-\varepsilon}=0.927$ and $p_{k-\omega}=0.924$ for the RNG k- $\varepsilon$ model and the SST k- $\omega$ model, respectively, both close to the model formal order in mesh number 2 $(h=1.73 \mathrm{~mm})$, which indicates that the asymptotic range has been reached. The analysis of these meshes indicates that the average approximate relative error in the indicator variables was $281 e_{a(k-\varepsilon)}=3.7 \%$ and $e_{a(k-\omega)}=3.4 \%$. The grid convergence index was $G C I_{k-\varepsilon}=4.9 \%$ and $G C I_{k-\omega}=4.4 \%$, respectively, revealing that in both cases numerical uncertainty remains within acceptable ranges as used in the literature. None of the indicator parameters of the mesh convergence analysis shows improvement at sizes below the size of mesh number 2 ( $h=$ $1.73 \mathrm{~mm}$ ). All subsequent analyses are conducted on results employing the mesh of $h=1.73 \mathrm{~mm}$. Clearly, both codes, OpenFOAM and $F L O W-3 D^{\circledR}$, respond differently to mesh size reduction.

\subsection{Sensitivity analysis}

This analysis was exclusively conducted using OpenFOAM results, as $F L O W-3 D^{\circledR}$ results have already been analyzed in Bombardelli et al. (2011).

As expected, second-order methods yield more accurate results than their first-order counterparts; however, all schemes tend to underestimate mean flow velocities with a consistent overestimation of flow depths. Differences between first- and second-order methods are small when predicting these variables (4\%), but they reach larger values (not shown herein) when predicting maximum TKE on step edges. The differences in the model outcome are small among different second-order discretization schemes (Fig. 5): both limited central-difference and limited

298 Van Leer discretization schemes yield differences in estimations below 4\% compared to 
experimental data for all the analyzed variables. Nevertheless, the limited central-difference scheme seems to systematically achieve accuracies between $5 \%$ and $10 \%$ higher employing approximately $30 \%$ smaller computational times than the Van Leer scheme.

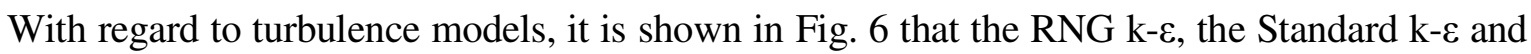
the Realizable k- $\varepsilon$ models yield virtually the same results (differences are on average below 1\%), as expected. On average terms, a slightly better performance can be attributed to the RNG k- $\varepsilon$ model in the prediction of certain variables, such as water depths or the profiles within the boundary layer, but this difference is not rather small. As depicted in Fig. 6, the SST k- $\omega$ model tends to overestimate water depths $(4 \%)$ with a consistent underestimation of velocities slightly above the SST k- $\varepsilon$ ( $2 \%$ overestimation of water depths). It can also be observed how the latter model yields more developed velocity profiles than the SST k- $\omega$ models, although these differences become insignificant when predicting velocity profiles within step cavities.

\subsection{Discussion of approaches and self-similarity analysis}

The flow depth throughout the stepped spillway is very well predicted by all approaches (see

Fig. 7). The first reach located over the smooth region near the spillway crest is reproduced with a root mean square error (RMSE) below 1\%. In the last steps, all approaches seem to overestimate the experimental results, although results with TruVOF are slightly closer to the experimental data.

318 The RMSE in the water profile estimation for the TruVOF method is $4.2 \%$, slightly below the $6.2 \%$ attained by the Partial VOF.

With regards to velocity profiles, the formation of a boundary layer is accurately captured by both methodologies (see Fig. 8), although rather significant differences can be observed among 
them. For example, the Partial VOF predicts more developed boundary layers than the TruVOF.

323 Both approaches tend to slightly underestimate the velocity values, although the Partial VOF achieves a smaller difference with the experimental data than the TruVOF method. This may be due, among other causes, to the fact that the TruVOF does not account for free-surface tangential stresses. In both cases, this velocity underestimation is consistent with the overestimation of flow depths discussed above.

Compared to the velocity profiles obtained through a very recent three-dimensional (3D) detached eddy simulation (Toro et al., 2017), the velocity profiles obtained in this work are very close to those of 3D simulations, confirming that the 2D approach can give useful results for most engineering purposes, and 3D results can be reserved for research.

In Fig. 9, the evolution of flow depths and boundary-layer development for both Partial VOF and TruVOF methods is presented. By extrapolating their trending curves, the approximate location of the inception point, i.e., where flow aeration starts, can be estimated. According to this extrapolation, Partial VOF predicted a distance to the inception point of $1.66 \mathrm{~m}$, whereas the TruVOF estimated $1.87 \mathrm{~m}$. Compared to the experimentally observed distance to the inception point, Partial VOF and TruVOF overestimated this variable by $14 \%$ and $30 \%$, respectively. It bears emphasis that the experimental data have uncertainties on its own given the difficulty of determining the precise location of the inception point due to unsteadiness.

The experimental results and the inception point location computed according to Chanson 341 (2002) are also included in Fig. 9. Compared to this dataset, the results of Partial vof and TruvOF 342 differ with experiments in $2 \%$ and $7 \%$, respectively, which is indeed accurate enough for 343 engineering purposes. A recent experimental work (Zhang \& Chanson, 2016a) states that the 344 inception point occurs where the boundary layer thickness reaches $80 \%$ of the water depth. Using 
this criterion, the Partial VOF and TruVOF estimate distances to the inception point of $1.33 \mathrm{~m}$ and $1.28 \mathrm{~m}$, respectively. Compared to the experimental data, the models underestimated this variable by $8 \%$ and $12 \%$, respectively. Toro et al. (2017) have very recently shown that cylindrical vortex tubes develop and evolve with space throughout the boundary layer growth, being responsible for the perturbations of the free surface which lead to air entrainment. The complex nature of these tubes can help understand the typical unsteadiness observed in the laboratory experiments and the difficulty of predicting the location of the inception point with accuracy.

As discussed above, a certain trend to yield more developed velocity profiles near the spillway crest is observed from the computations using Partial VOF, resulting in a clear overestimation of the boundary-layer thickness within this region $(L<0.75 m)$.

Meireles (2011) and Toro et al. (2016) proposed and corroborated self-similarity of turbulence statistics in stepped spillways, an unprecedented result. Similarly, Felder and Chanson (2011) discussed self-similarity of the integral time scales in terms of similar trends in the flow distributions along the cavity. However, there was no clear description of the self-similarity in the flow velocity within the cavity, as no negative velocities were recorded in the recirculation region. Previously, in Gonzalez and Chanson (2004), similar trends of the flow velocity within the cavity 361 were presented; in that study, non-dimensional velocities were obtained by using the velocity at 362 which half of the freestream velocity is reached.

363 In the case presented herein, the results show the occurrence of a certain pattern in the velocity 364 and TKE distributions throughout the spillway (see Fig. 10). Using a suitable normalization, most 365 of flow variables present self-similar behavior throughout the spillway. This fact was investigated by using exclusively $O p e n F O A M$ data and the results indicate approximate flow self-similarity. 
Fig. 11 shows the normalized profiles of velocity, TKE, dissipation rate and pressure at different step edges compared with the results reported in previous works for the velocities. These profiles show an important degree of overlapping. Additionally, it was observed that the highest pressures always occur close to the pseudo-bottom at approximately $0.32 \mathrm{~cm}$ upstream of the step edges (cf. also with Toro et al., 2016).

A self-similar behavior can also be observed in the step cavities, as depicted in Fig. 12, although the differences in the velocity profiles discussed above are not apparent. The velocity profiles predicted by the model in the recirculation zone attain an accuracy of $93.3 \%$, compared to data by Amador et al. (2006). The same authors state that the maximum recirculation velocity is $15 \%$ of $U_{\max }$, which is confirmed by the results presented herein. With regards to pressure profiles, it can be observed that this variable drastically drops below the hydrostatic profile in the recirculation region, even attaining negative values, as reported in Toro et al. (2016). It can also be observed that this pressure drop reaches higher values as the distance to the crest increases. the pseudo-bottom, thus corroborating that the flow in the pseudo-bottom vicinity is responsible for the highest dissipation rates of TKE (Toro et al., 2016, 2017). It was also observed that the dissipation rate profiles perfectly reproduce the shape of the integral turbulent length scale profiles reported in Amador et al. (2006). Toro et al. $(2016,2017)$ additionally found in the 3D detached eddy simulations that the pseudo-bottom is where vorticity and production of TKE both present a peak, highlighting the tremendous importance of such plane in shedding the tubular structures which are responsible for the deformation of the free surface and, thus, for the air entrainment.

\section{Final remarks and conclusions}


A numerical model, able to reproduce the behavior of the non-aerated region of the flow in stepped spillways, has been implemented using OpenFOAM. For its validation, experimental data previously collected at LNEC were used. After conducting a mesh-convergence analysis, the sensitivity to turbulence model, treatment of the free surface and numerical discretization scheme was assessed.

Numerical results indicate that the use of a Partial VOF instead of the TruVOF does not affect decisively the predictions of flow velocities and turbulence statistics, although more accurate results can be attributed to the Partial VOF. This result is especially important given the imposition of boundary conditions at the free surface in the TruVOF, which makes it the most cost-effective choice in terms of computational expenses in cases where no strong air-water interaction is expected.

The results obtained with several RANS k- $\varepsilon$ turbulence models indicate that their predictions of virtually all variables differ less than $1 \%$. The RNG k- $\varepsilon$ model performs marginally better, whereas the Standard k- $\varepsilon$ and the Realizable k- $\varepsilon$ yield virtually the same results. The SST k- $\omega$ model, in turn, overestimates the water depths by $4 \%$, with a consistent underprediction of velocities. Differences are more important than those obtained with the models of the k- $\varepsilon$ family while solving the flow within the viscous sub-layer. This suggests, at least for this particular case, the benefit of using the RNG k- $\varepsilon$ for its smaller computational cost and higher accuracy 408 compared to the SST k- $\omega$.

409 The model sensitivity to different numerical discretization schemes shows that the limited 410 central-difference scheme performs slightly better and at smaller computational costs than the 411 limited Van Leer model, although both second-order schemes yield similar results for velocities 
and water depths. Its larger accuracy and low computational cost compared to other second-order schemes makes the limited central-difference the most suitable scheme for cases of this nature. stepped spillways, proposed by our research group elsewhere, was further confirmed in this paper. It was also found that the pressure near step edges raises above the hydrostatic profile, being the maximum value slightly upstream of the step edge. Additionally, special attention is placed on the flow self-similarity within the step cavities, finding that the model presented herein correctly reproduces the data available in the literature for recirculation velocities.

\section{Acknowledgments}

This study was made possible due to the financial support of the PhD program "VALi+D", funded by Generalitat Valenciana (Spain).

The second author acknowledges the support of the National Commission for Scientific and Technological Research (CONICYT), through a "Becas Chile" fellowship.

\section{References}

Amador, A., 2005. Comportamiento hidráulico de los aliviaderos escalonados en presas de hormigón compactado. Universitat Politècnica de Catalunya, Barcelona (Spain) (in Spanish). region in a stepped spillway by PIV. J. Fluids Eng. 128, 1266-1273.

Amador, A., Sánchez-Juny, M., Dolz, J., 2006. Characterization of the nonaerated flow

Bayon, A., Lopez-Jimenez, P.A., 2015. Numerical analysis of hydraulic jumps using OpenFOAM. J. Hydroinformatics 17, 662-678. doi:10.2166/hydro.2015.041 

Performance assessment of OpenFOAM and FLOW-3D in the numerical modeling of a low Reynolds number hydraulic jump. Environ. Model. Softw. 80, 322-335. impact onto a liquid layer of finite thickness: Dynamics of the cavity evolution. Physical Review E, 79(3), p.036306.

Berberovic E., 2010. Investigation of free-surface flow associated with drop impact: numerical simulations and theoretical modeling, Ph.D. thesis, Technische Universität (Germany). Hydraul. Eng. 129, 661-670.

Bombardelli, F.A., Hirt, C.W., García, M.H., Matthews, B.W., Fletcher, C.A.J., Partridge, A.C., Vasquez, S., 2001. Computations of curved free surface water flow on spiral concentrators.

Bombardelli, F.A., Meireles, I., Matos, J., 2011. Laboratory measurements and multi-block numerical simulations of the mean flow and turbulence in the non-aerated skimming flow region of steep stepped spillways. Environ. Fluid Mech. 11, 263-288. $18,45-54$.

Carvalho, R.F., Amador, A.T., 2009. Physical and numerical investigation of the skimming flow over a stepped spillway. Adv. Water Resour. Hydraul. Eng. 1767-1772.

Carvalho, R.F., Lemos, C.M., Ramos, C.M., 2008. Numerical computation of the flow in hydraulic jump stilling basins. J. Hydraul. Res. 46, 739-752. doi:10.1080/00221686.2008.9521919 

for Estimation and Reporting of Uncertainty Due to Discretization in CFD Applications. J. Fluids Eng. 130, 078001-078001. doi:10.1115/1.2960953 $634-634$.

Chanson, H., Bung, D., and Matos, J. (2015). Stepped spillways and cascades, in Energy

Dissipation in Hydraulic Structures. IAHR Monograph, CRC Press, Taylor and Francis Group, Leiden, The Netherlands, H. CHANSON Editor, pp. 45-64 (ISBN 978-1-138-02755-8). (Record at UQeSpace).

Felder, S., Chanson, H., 2009. Energy dissipation, flow resistance and gas-liquid interfacial area in skimming flows on moderate-slope stepped spillways. Environ. Fluid Mech. 9, 427-441.

Felder, S., and Chanson, H., 2011. Air-water flow properties in step cavity down a stepped chute. Int. J. Multiph. Flow, 37(7), 732-745.

Ferziger, J.H., Peric, M., 2012. Computational methods for fluid dynamics. Springer Science and Business Media.

FLOW-3D ${ }^{\circledR}$ User Manual, 2016. FLOW-3D User Manual. Flow Science.

Frizell, K.W., Renna, F.M., Matos, J., 2013. Cavitation potential of flow on stepped spillways. J. Hydraul. Eng. 139, 630-636. stepped spillways”. J. Hydraul. Eng., 141 (8), 07015009.

Gonzalez, C. A., and Chanson, H., 2004. Interactions between cavity flow and main stream skimming flows: an experimental study. Can. J. of Civil Eng., 31(1), 33-44. 
Hirt, C.W., Nichols, B.D., 1981. Volume of fluid (VOF) method for the dynamics of free boundaries. J. Comput. Phys. 39, 201-225. doi:10.1016/0021-9991(81)90145-5

Launder, B.E. and Sharma, B.I., 1974. Application of the energy-dissipation model of turbulence to the calculation of flow near a spinning disc. Letters in heat and mass transfer, 1(2), pp.131-137.

Matos, J., 1999. Emulsionamento de ar e dissipação de energia do escoamento em descarregadores em degraus, Ph.D. Thesis, IST, Portugal (in portuguese).

Matos, J., Meireles, I., 2014. Hydraulics of stepped weirs and dam spillways: engineering challenges, labyrinths of research, In "Hydraulic Structures and Society - Engineering Challenges and Extremes", The University of Queensland, Brisbane, Australia, Proc. of the 5th Australia, H. Chanson and L. Toombes Editors, 30 pp. 498 Portugal (in Portuguese).

499 Meireles, I., Matos, J., 2009. Skimming flow in the nonaerated region of stepped spillways 500 over embankment dams. J. Hydraul. Eng. 135, 685-689.

501 Meireles, I., 2011. Hydraulics of stepped chutes: experimental-numerical-theoretical study. 502 Ph.D. thesis, Univ. of Aveiro, Portugal. 

stepped spillways over roller compacted concrete dams. J. Hydraul. Eng. 138, 870-877. steep stepped spillways: an analysis. J. Hydraul. Res. 52, 375-385. AIAA Paper 93-2906.

OpenFOAM User Guide, 2011. OpenFOAM: The Open Source CFD Toolbox User Guide. The Free Software Foundation Inc.

Patankar, S.V., Spalding, D.B., 1972. A calculation procedure for heat, mass and momentum transfer in three-dimensional parabolic flows. J Heat Mass Transf. 15, 1787-1806. doi:10.1016/0017-9310(72)90054-3.

514 Renna, F., 2004. Caratterizzazione Fenomenologica del Moto di un Fluido Bifasico lungo

515 Scaricatori a Gradini, Ph.D. thesis, Politecnico di Bari, Cosenza, Italy (in Italian).

Roache, P. J., 2009. Fundamentals of verification and validation. Hermosa Publishers, New Mexico, USA. reach. Water Resources Management, 18(3), 177-199.

Rusche, H., 2002. Computational fluid dynamics of dispersed two-phase flows at high phase fractions. Imperial College of Science, Technology and Medicine (UK). 
Schlichting, H., Gersten, K., 2000. Boundary-Layer Theory, 8th Edition. ed. Springer. model for high reynolds number turbulent flows. Comput. Fluids 24, 227-238. doi:10.1016/0045-7930(94)00032-T

Sweeney, B.P., 2014. Converged stepped spillway models in OpenFOAM. Kansas State

University.

Toro, J.P., Bombardelli, F.A., Paik, J., Meireles, I., Amador, A., 2016. Characterization of turbulence statistics on the non-aerated skimming flow over stepped spillways: A numerical study. Environ. Fluid Mech. 1-27.

Toro, J.P., Bombardelli, F.A. and Paik, J., 2017. Detached eddy simulation of the nonaerated skimming flow over a stepped spillway. J. of Hydraulic Eng. 143(9), 04017032.

Ubbink, O., 1997. Numerical prediction of two fluid systems with sharp interfaces, PhD Thesis, Imperial College of Science, Technology and Medicine (UK).

Van Leer, B., 1977. Towards the ultimate conservative difference scheme III. Upstreamcentered finite-difference schemes for ideal compressible flow. J. Comput. Phys. 23, 263-275.

Witt, A., Gulliver, J., Shen, L., 2015. Simulating air entrainment and vortex dynamics in a hydraulic jump. Int. J. Multiph. Flow 72, 165-180.

Yakhot, V., Orszag, S., Thangam, S., Gatski, T., Speziale, C., 1992. Development of turbulence models for shear flows by a double expansion technique. Phys. Fluids Fluid Dyn. 1989-1993 4, 1510-1520.

Zhang G, Chanson H (2016a) Hydraulics of the Developing Flow Region of Stepped Spillways. I: Physical Modeling and Boundary Layer Development. J Hydraul. Eng. ASCE 04016015. 
549 Zhang G, Chanson H (2016b) Hydraulics of the Developing Flow Region of Stepped 550 Spillways. II: Pressure and Velocity Fields. J. Hydraul. Eng. ASCE 04016016.

551 


\section{Figures}

Figure 1. Geometry of the case study and details of the spillway crest zone. Adapted from Bayon et al. (2015).

Figure 2. Experimental stepped spillway facility at the LNEC, used for experimental validation (Matos, 1999; Meireles, 2004, 2011; Renna, 2004).

Figure 3. Detail of mesh of the spillway crest zone.

Figure 4. Water free surface profiles (left) and velocity profiles (right) at $L=1.04 m$ (step $23)$ as a function of mesh element minimum size $(\Delta x)$, with a first-order upwind scheme, Partial VOF and the RNG $k-\varepsilon$ model, compared against experimental data. Unfilled symbols indicate measurements affected by fluctuations either of the free surface or the inception point position.

Figure 5. Numerical results using RNG $k-\varepsilon$ model and diverse discretization schemes, with a converged mesh size of $\Delta x=1.5 \mathrm{~mm}$. a) Water free surface profiles; b) Velocity profile at step $23(L=1.04 m)$; c) Velocity profile within the cavity at $L=1.072 m$. For the experimental data, unfilled symbols indicate measurements affected by either the fluctuations of the free surface or the location of the inception point. 
Figure 6. Numerical results using a limited central-difference discretization scheme and diverse turbulence models, with a converged mesh size of $\Delta x=1.5 \mathrm{~mm}$. a) Water free-surface profiles; b) Velocity profile at step $23(L=1.04 m)$; c) Velocity profile within the cavity at $L=1.072 \mathrm{~m}$. For the experimental data, unfilled symbols indicate measurements affected by either the fluctuations of the free surface or the location of the inception point.

Figure 7. Water free-surface profile using RNG $k-\varepsilon$ model and first-order upwind discretization scheme and a converged mesh size of $\Delta x=1.5 \mathrm{~mm}$ according to type of VOF method: Partial VOF (OpenFOAM) and TruVOF (FLOW-3D®).

Figure 8. Velocity profiles using RNG $k-\varepsilon$ model and a first-order upwind discretization scheme and a converged mesh size of $\Delta x=1.5 \mathrm{~mm}$ according to type of VOF method: Partial VOF (OpenFOAM) and TruVOF (FLOW-3D®).

Figure 9. Distribution of water depths, boundary-layer development and estimated inception point of air entrainment profile using RNG $k-\varepsilon$ model and a first-order upwind discretization scheme and a converged mesh size of $\Delta x=1.5 \mathrm{~mm}$ according to type of VOF method: Partial VOF (OpenFOAM) and TruVOF (FLOW-3D) with validation using experimental data and literature.

Figure 10. Velocity and TKE fields throughout the spillway obtained with OpenFOAM using a converged mesh $(\Delta x=1.5 \mathrm{~mm})$, an upwind first-order discretization scheme and the RNG $k-\varepsilon$ model. 
598 Figure 11. Profiles of normalized velocity, turbulent kinetic energy (TKE), dissipation rate 599 of TKE and pressure at different step edges using RNG $k-\varepsilon$ model and a first-order upwind 600 discretization scheme and a converged mesh size of $\Delta x=1.5 \mathrm{~mm}$. In the pressure plot, unfilled 601 symbols correspond to pressure profiles $0.32 \mathrm{~cm}$ upstream of step edges, where maximum 602 pressure occurs, and $p_{0}$ is the hydrostatic pressure at the pseudo-bottom.

603

604 Figure 12. Profiles of normalized velocity, turbulent kinetic energy (TKE), dissipation rate 605 of TKE and pressure at different step gaps using RNG $k-\varepsilon$ model and a first-order upwind 606 discretization scheme and a converged mesh size of $\Delta x=1.5 \mathrm{~mm}$.

607

608

609

610 


\section{Local Coordinate System (LCS)}

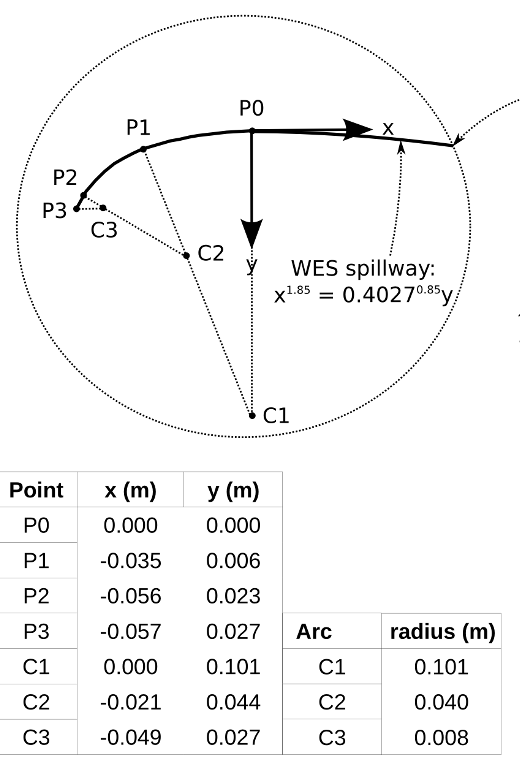

\section{Global Coordinate System (GCS)}

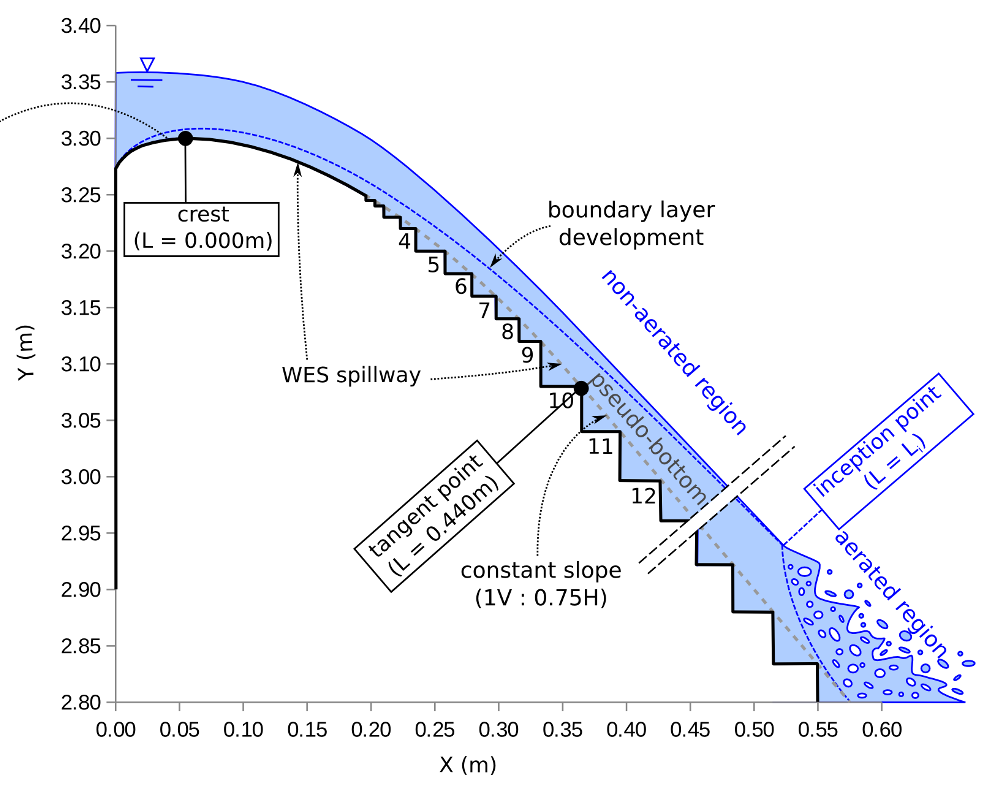




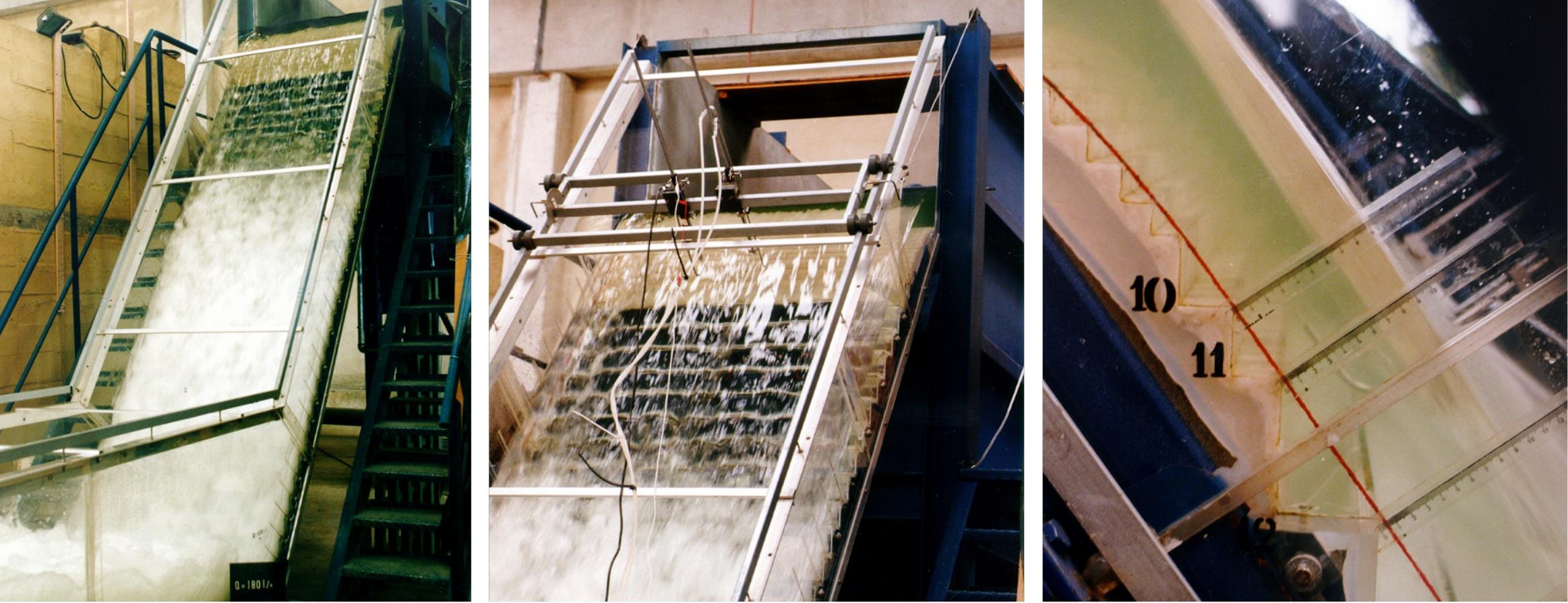




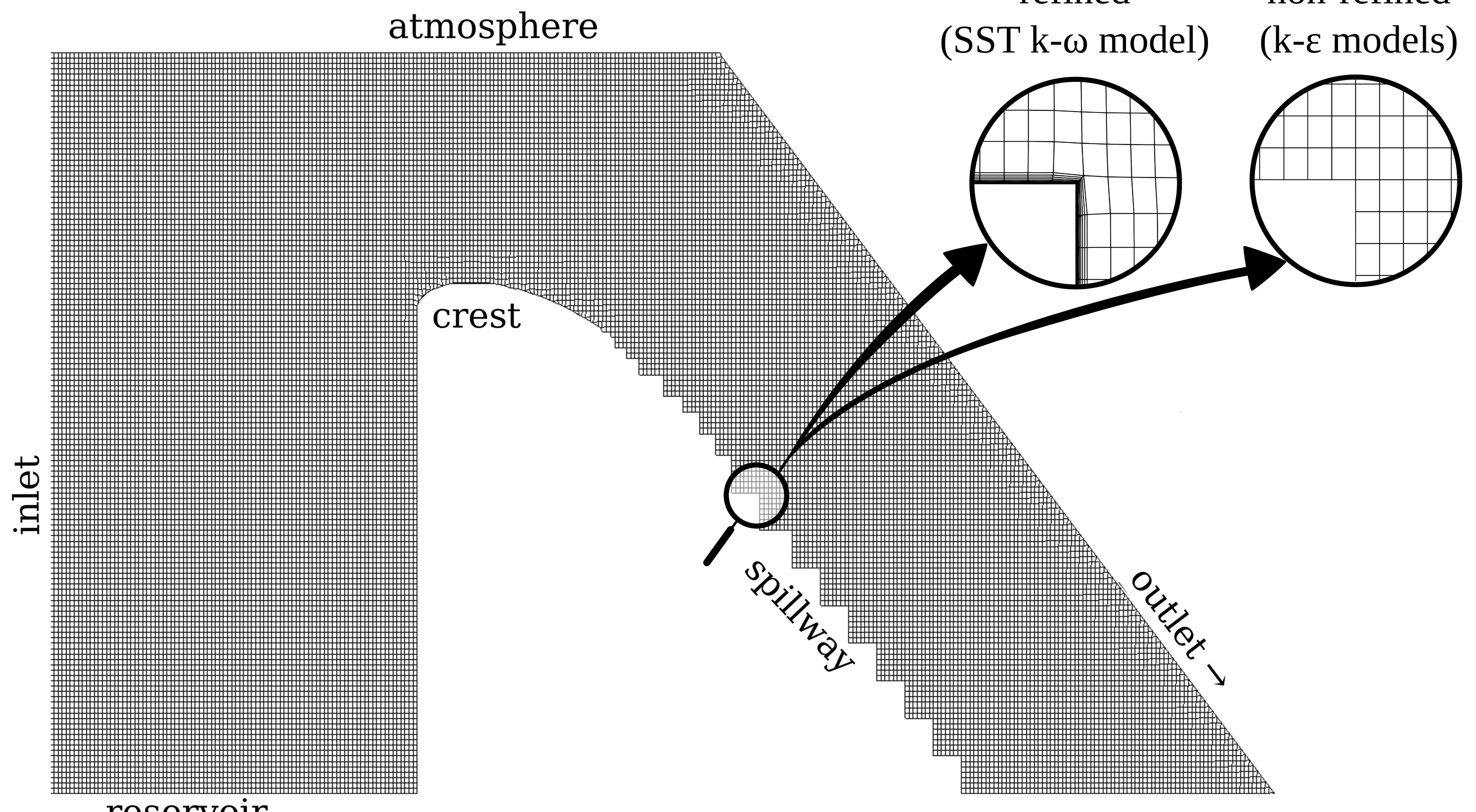



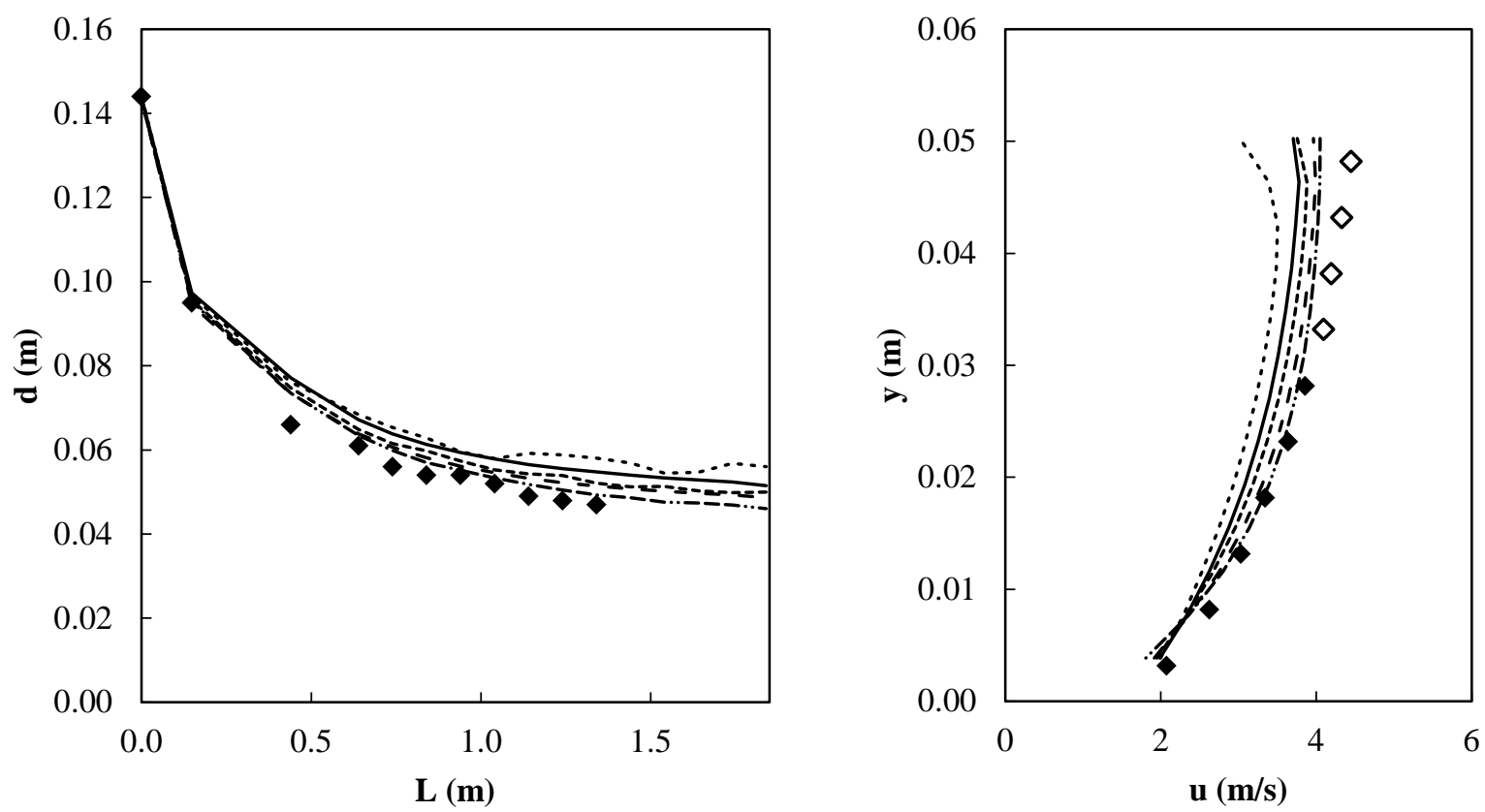

$\Delta x=1.1 \mathrm{~mm}---\Delta \mathrm{x}=1.5 \mathrm{~mm}-\cdot--\cdot-\Delta \mathrm{x}=2.1 \mathrm{~mm}$ 

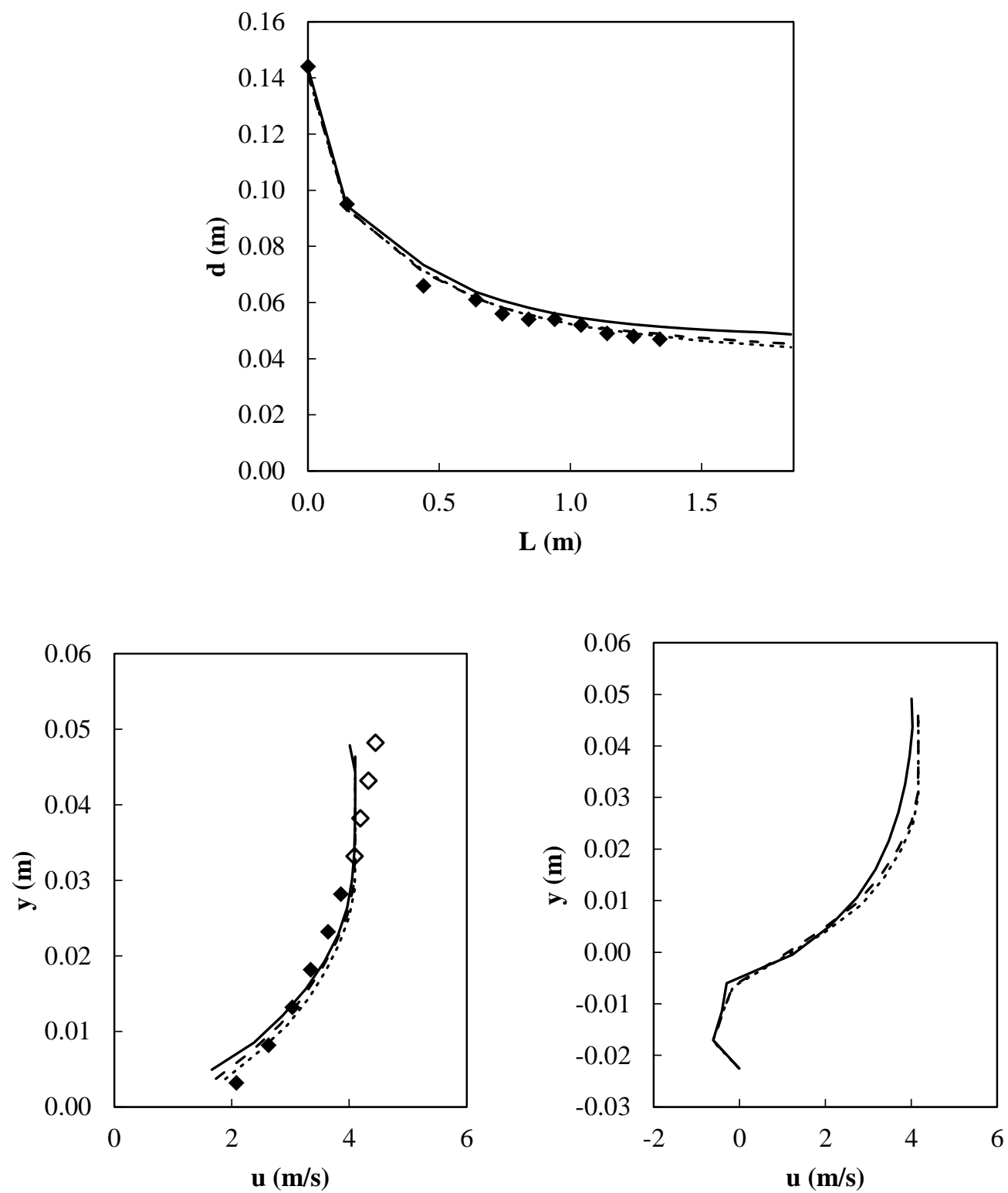

— 1st order upwind $\quad \cdots \cdot$.... Limited Linear $\quad$ - - Van Leer $\quad$ Experimental 

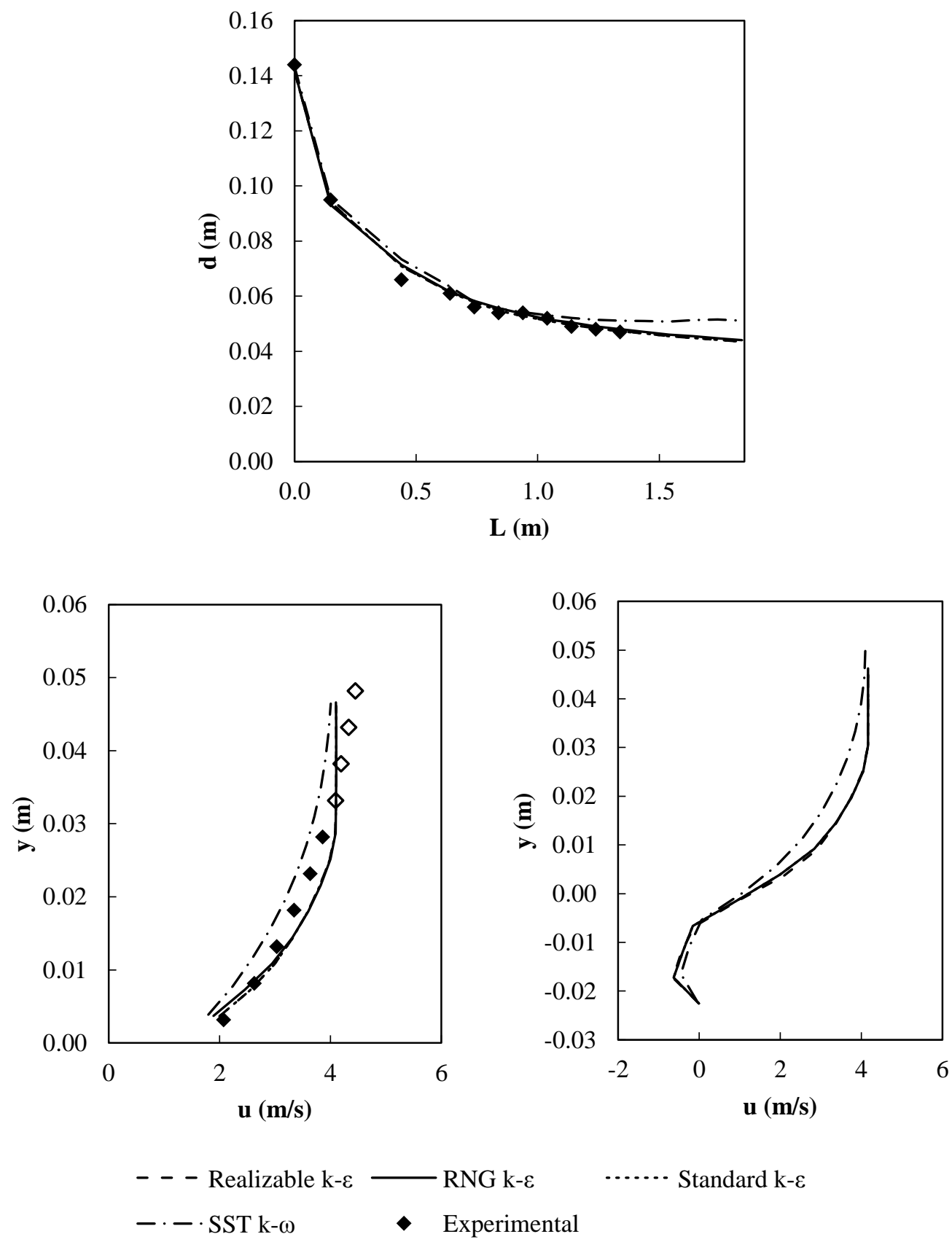


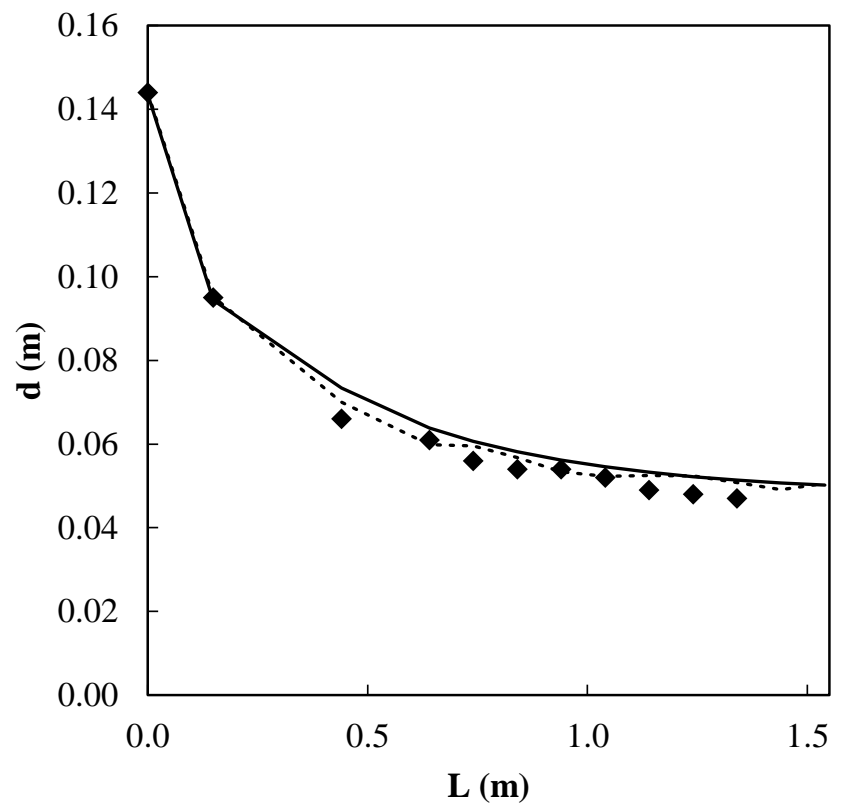

— OpenFOAM …...FLOW-3D • Experimental 

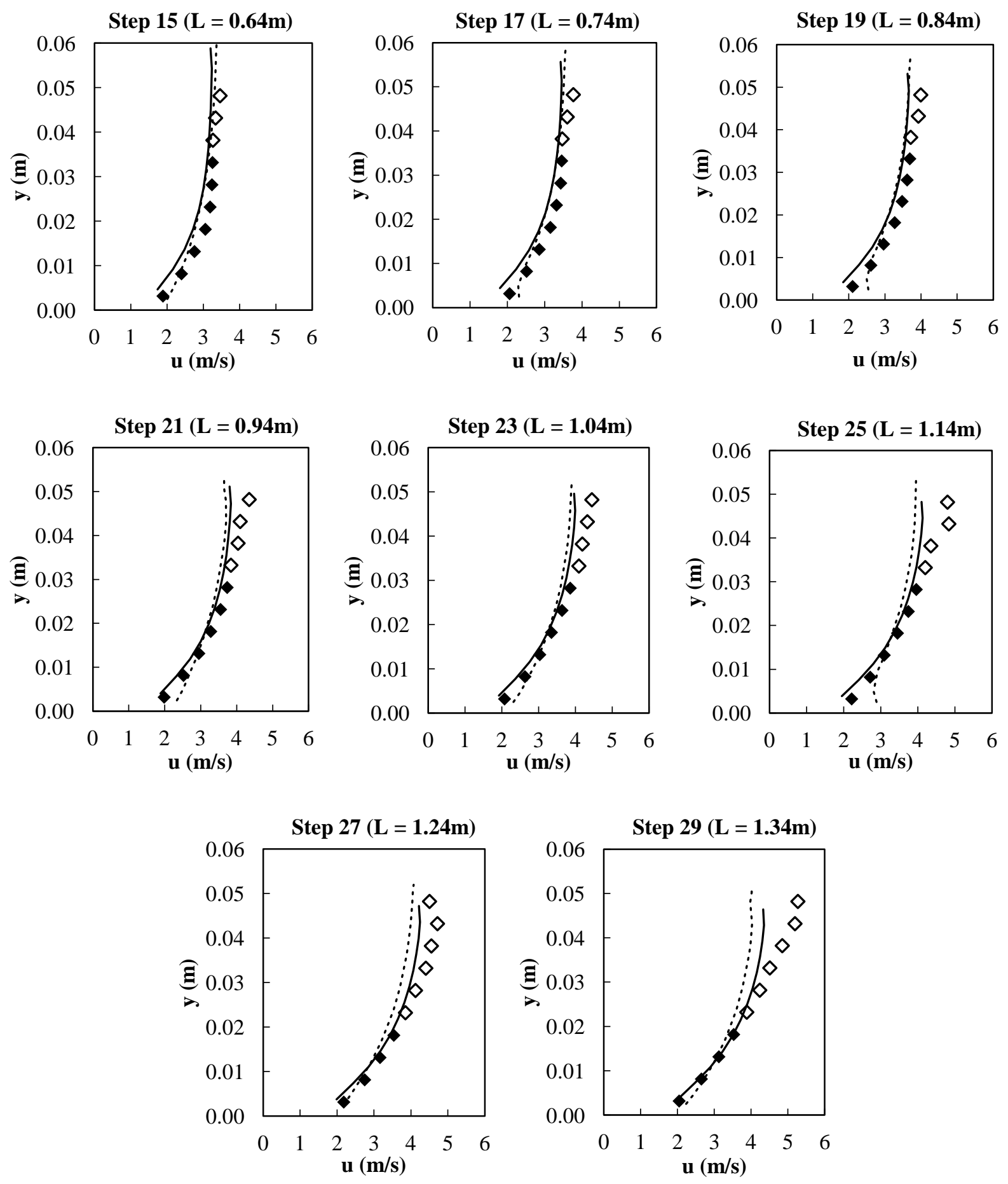

- OpenFOAM

…...FLOW-3D

- Experimental 


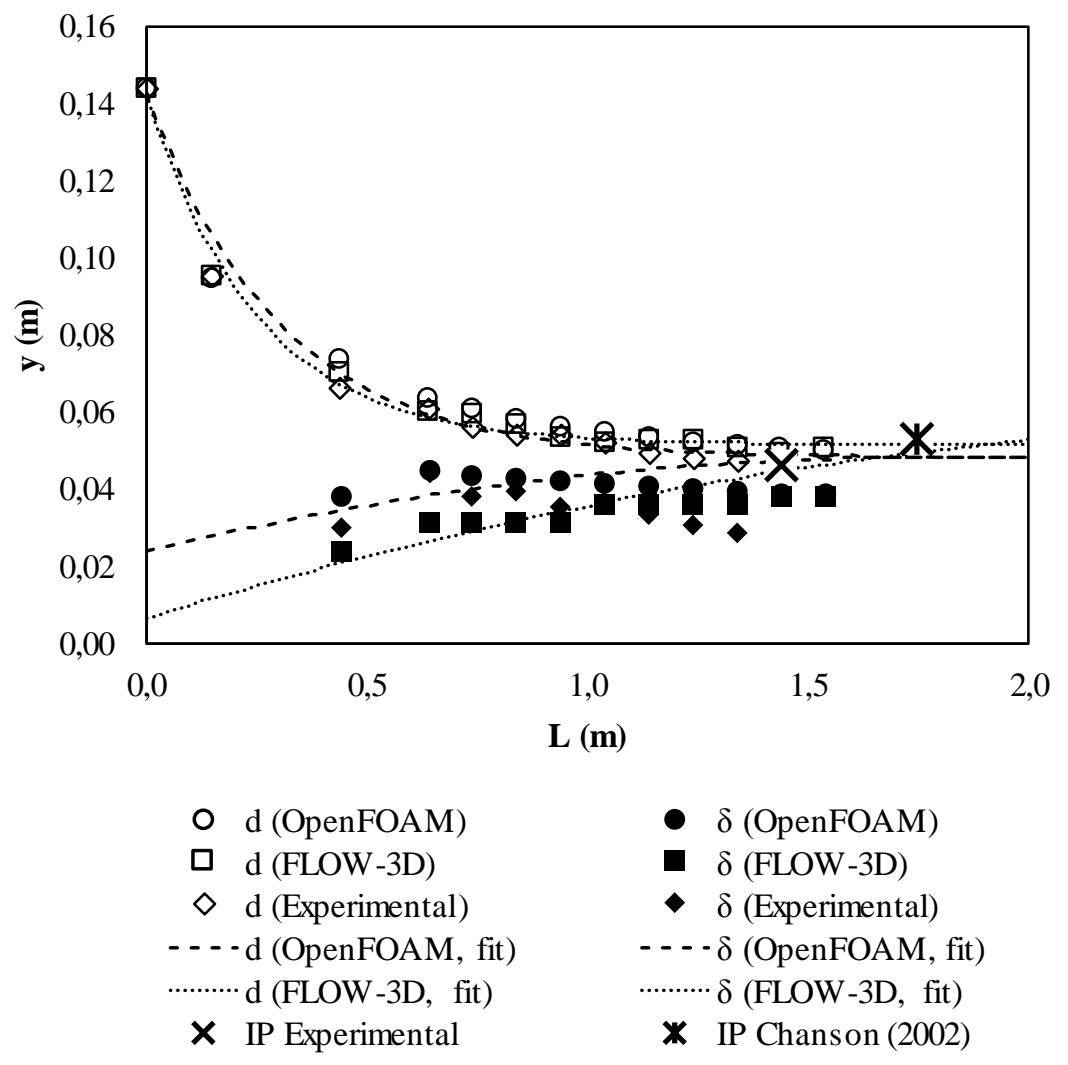




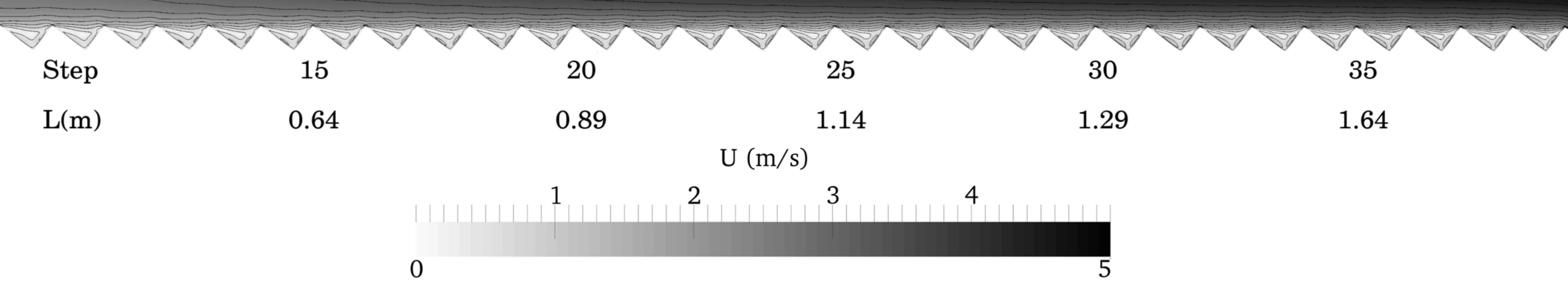

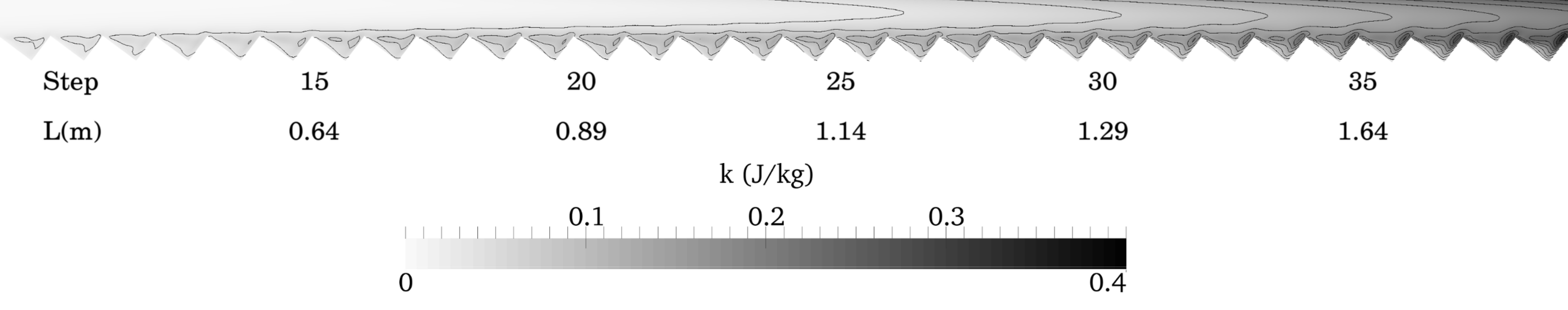



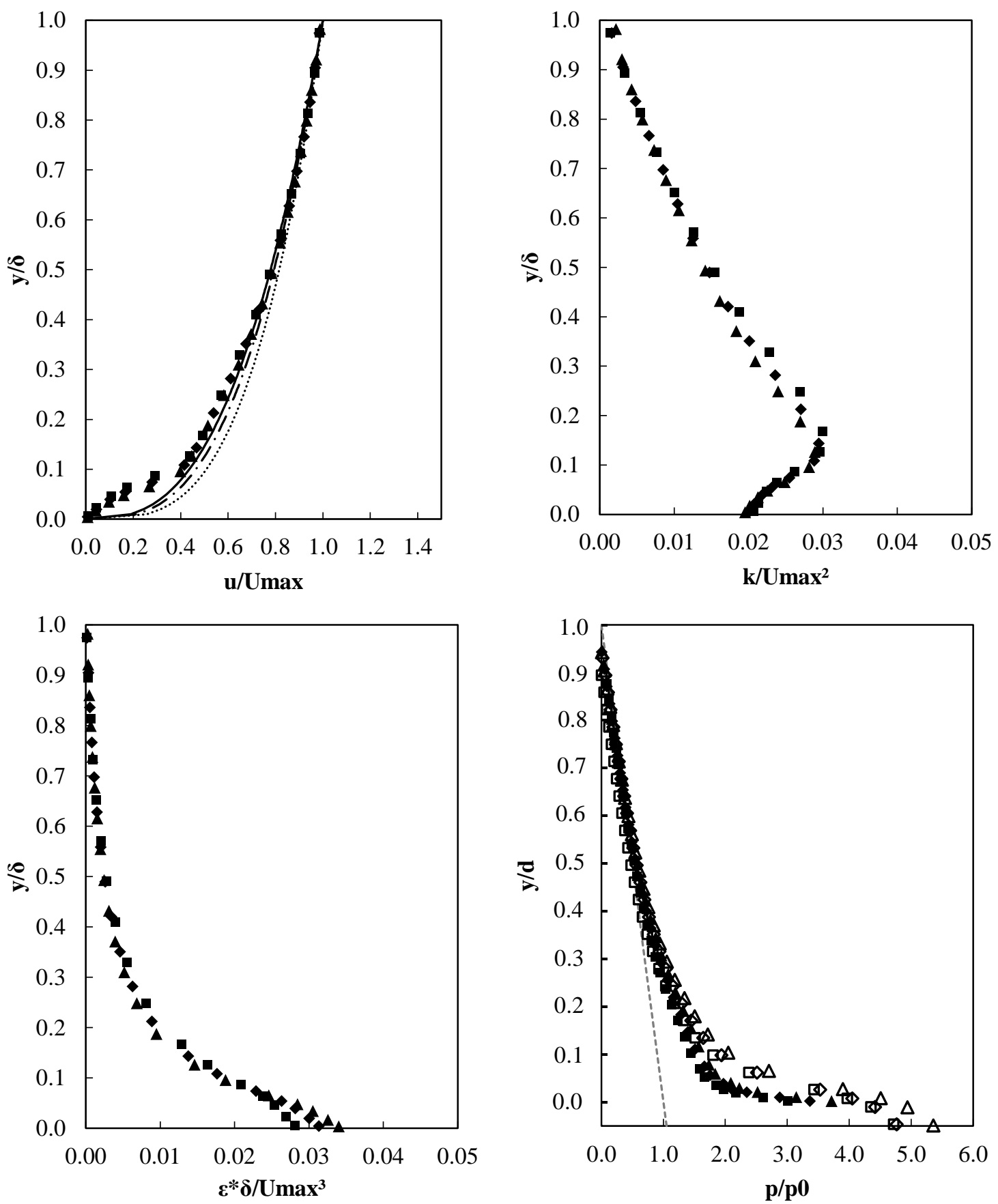

- $\quad$ Step $19(\mathrm{~L}=\overline{0} .84 \mathrm{~m})$

- Step $23(\mathrm{~L}=1.04 \mathrm{~m})$

\ $\quad$ Step $27(\mathrm{~L}=1.24 \mathrm{~m})$ Meireles et al. (2012) 

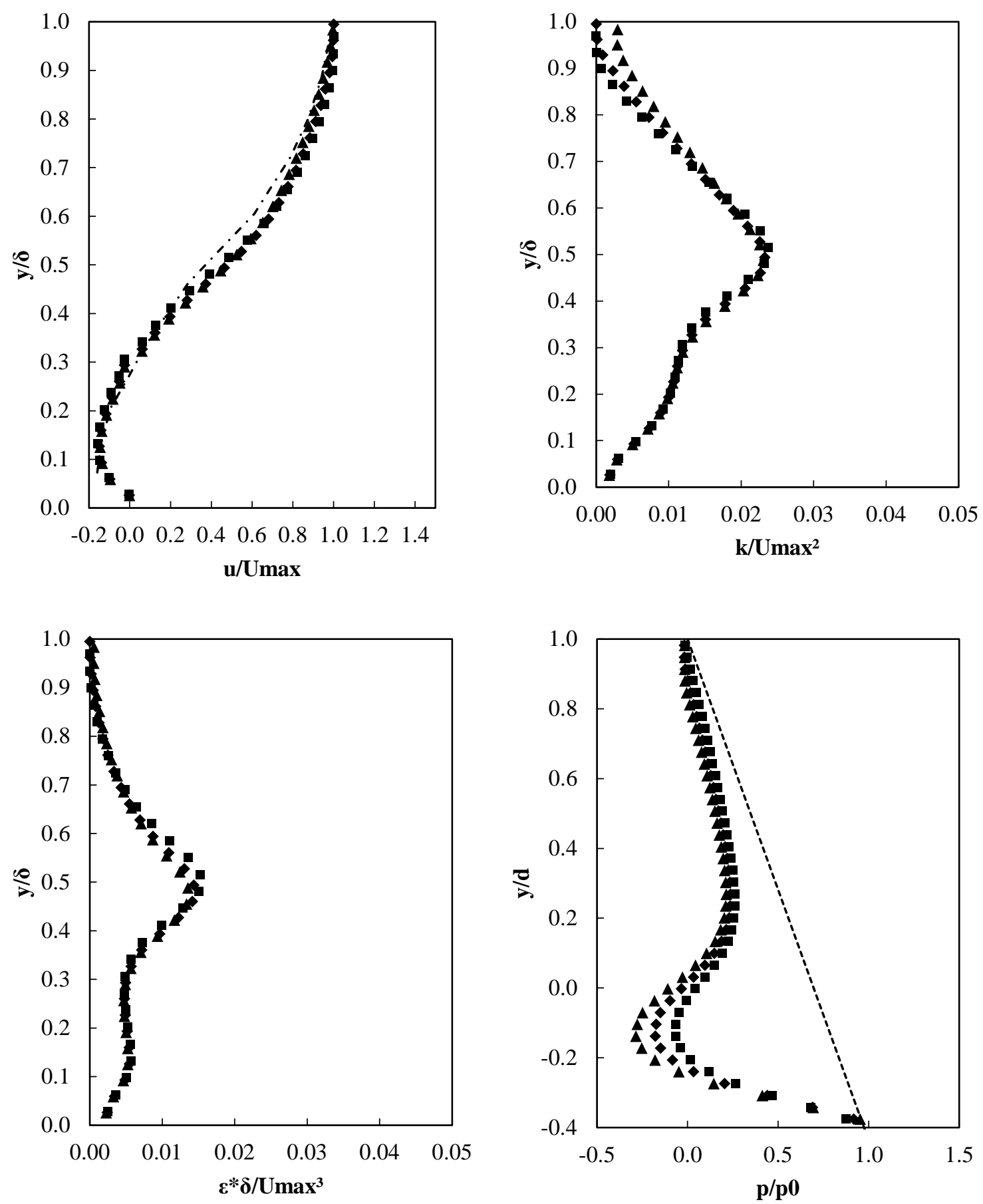

- $\mathrm{L}=0.872 \mathrm{~m}$

- L=1.072m

- $\mathrm{L}=1.272 \mathrm{~m}$

------ Hydrostatic

- - - Amador et al. (2006) 